\title{
New Drug and Possible New Toxicity - Squamous Cell Carcinoma Following Imatinib in Patients with Gastrointestinal Stromal Tumors
}

\author{
FAISAL INAYAT ${ }^{1}$ and MUHAMMAD WASIF SAIF ${ }^{2}$ \\ ${ }^{1}$ Department of Medicine, New York-Presbyterian Hospital, Weill Cornell Medical College, New York, NY, U.S.A.; \\ ${ }^{2}$ Department of Hematology/Oncology, Tufts Medical Center, \\ Tufts University School of Medicine, Boston, MA, U.S.A.
}

\begin{abstract}
Background: Molecularly targeted therapy has revolutionized the treatment of advanced gastrointestinal stromal tumors (GISTs). Specifically, the consistent dependence of GISTs on proto-oncogene c-KIT signaling led to the development and successful implementation of imatinib, a small-molecule c-KIT inhibitor. Imatinib induces, rapid and sustained clinical benefit by blocking the signaling via c-KIT. The most frequently reported adverse reactions (>30\%) include edema, nausea, vomiting, muscle cramps, musculoskeletal pain, diarrhea, rash, fatigue and abdominal pain. Case Series: Herein, we report a case series of cutaneous squamous cell carcinoma (SCC) occurring secondary to imatinib in two patients treated for GISTs. Both patients were successfully managed with surgical resection of SCC and the discontinuation of the drug. Furthermore, we undertook a comprehensive literature review on this association. Few cases of cutaneous SCC secondary to imatinib therapy were reported in patients with chronic myeloid leukemia. However, there was no clinical evidence on causation of imatinib-associated SCC in patients with GIST. Conclusion: To our knowledge, the present report is the first to describe imatinib-related SCC in patients undergoing treatment for GISTs. This implicates that safety and long-term tolerability of imatinib in patients with GISTs warrant rigorous testing and close monitoring.
\end{abstract}

Gastrointestinal stromal tumors (GISTs) are rare tumors of the gastrointestinal tract characterized by cell-surface expression of the proto-oncogene c-KIT. Imatinib mesylate is a potent and

Correspondence to: Professor M. Wasif Saif, MD, MB, BS, Director, GI Oncology Program; Leader, Experimental Therapeutics, Tufts University School of Medicine, Tufts Medical Center, South Building, 8th Floor; 800 Washington St., Box 245. Boston, MA 02111, U.S.A. Tel: +1 6176366227, Fax: +1 6176368538, e-mail: WSaif@tuftsmedicalcenter.org

Key Words: Gastrointestinal stromal tumors, imatinib, squamous cell carcinoma, skin toxicity, tyrosine kinase inhibitor, drug safety, adverse effect. selective tyrosine kinase inhibitor of breakpoint cluster regionAbelson (BCR-ABL) gene, c-KIT, and platelet-derived growth factor receptor A (PDGFRA). It is a first-line standard therapy for inoperable, metastatic, or recurrent KIT-positive GIST and for the adjuvant treatment of patients following resection of primary KIT-positive GIST (1).

After the clinical introduction of imatinib, the therapeutic strategy for GISTs dramatically changed. Imatinib has become one of the hallmarks of targeted therapy developments in oncology. It has dramatically improved the patient outcomes for GIST, with impact on both quality of life and long-term prognosis (2).

The toxicity profile of imatinib has been well characterized. Although the majority of patients experience an adverse event during treatment with imatinib, these side-effects are usually mild and manageable, with the majority of patients continuing treatment uninterruptedly (3). However, the present report highlights an unusual and serious adverse effect of imatinib in patients with GISTs in the form of cutaneous squamous cell carcinoma (SCC).

Imatinib induced-SCC has been reported in patients with chronic myeloid leukemia $(4,5)$. However, the present study represents the first report highlighting SCC following imatinib in patients with GIST. It prompts that clinicians should maintain a high index of suspicion for SCC in such patients.

\section{Case Series}

Case Report 1. The first patient case is of a 90-year-old woman who initially presented to the hospital after routine laboratory studies for anemia. Upper gastrointestinal endoscopy showed $4 \times 5 \mathrm{~cm}$ mass with central cavitation. Endoscopic ultrasound (EUS) revealed a mass in the cardia which measured $32 \mathrm{~mm}$ in the long axis and $17 \mathrm{~mm}$ in luminal diameter. Computed tomography of the chest showed a large hiatal hernia with marked thickening of the distal esophagus. There was an 11 $\mathrm{mm}$ enlarged lymph node adjacent to the gastroesophageal junction below the diaphragm, which was suspicious for lymph 
Table I. Cases of squamous cell carcinoma following imatinib therapy reported in literature.

\begin{tabular}{|c|c|c|c|c|c|c|c|c|}
\hline $\begin{array}{l}\text { Case } \\
\text { no. }\end{array}$ & $\begin{array}{l}\text { Age } \\
\text { (years) }\end{array}$ & Gender & Diagnosis & $\begin{array}{l}\text { Dose of } \\
\text { imatinib } \\
\text { (mg/day) }\end{array}$ & $\begin{array}{l}\text { Time from start } \\
\text { of imatinib } \\
\text { to SCC }\end{array}$ & $\begin{array}{l}\text { Other possible etiologies/ } \\
\text { risk factor for SCC, } \\
\text { except sun exposure }\end{array}$ & $\begin{array}{l}\text { Outcome/ } \\
\text { treatment }\end{array}$ & Reference \\
\hline 1 & 72 & M & CML & 600 & 15 Months & Hydroxyurea administration & $\begin{array}{l}\text { Successful resection } \\
\text { and irradiation }\end{array}$ & 4 \\
\hline 2 & 73 & M & CML & 600 & 2 Years & Hydroxyurea administration & Successful resection & 4 \\
\hline 3 & 70 & M & CML & 300 & 6 Years & None & Successful resection & 5 \\
\hline 4 & 90 & $\mathrm{~F}$ & GIST & 400 & 2 Years & None & Successful resection & Present case series \\
\hline 5 & 61 & F & GIST & 400 & 1 Year & None & Successful resection & Present case series \\
\hline
\end{tabular}

CML, Chronic myeloid leukemia; GIST, gastrointestinal stromal tumor; SCC, squamous cell carcinoma; M, male; F, female.

node metastasis. Pathology reports of the lesion were positive for c-KIT and negative for S100, smooth muscle actin and desmin, compatible with GIST. No mitotic activity or tumor necrosis was identified in that limited biopsy sample. She was transfused with 1 unit of packed red blood cells and given 200 $\mathrm{mg}$ intravenous iron sucrose prior to discharge.

The patient had been administered $400 \mathrm{mg} /$ day imatinib mesylate (Gleevec ${ }^{\circledR}$, Novartis) for her GIST for 2 years. While her GIST was well-controlled, a small superficial mass emerged on her left anterior shoulder (Figure 1A). It rapidly developed into a $3-\mathrm{cm}$, ulcerated, reddish nodule with an erythematous halo within 1 month (Figure 1B). Excisional biopsy was performed and the specimen was sent for histopathologic analysis (Figure 1C). Histopathology showed dermal lobules of moderately atypical squamous cells with frequent mitoses and small focal areas of keratinization. There were areas with glandular differentiation and mucin deposition highlighted with Mucicarmine stain.

Computed tomography appeared grossly unchanged, with no metastatic disease, swollen lymph nodes or visceral involvements. Immunohistochemistry showed that tumor cells were strongly positive for p63 and cytokeratin 7. The clinical and histopathological findings led to the diagnosis of SCC with moderate to poor glandular differentiation. Additional resection with 2-cm margin from the postoperative scar was performed.

Following the initial excision of SCC in our patient, three more suspicious growths appeared on her arms and back. Her dermatological surgeon biopsied the lesions and histopathologic evaluation confirmed the diagnosis of SCC. Imatinib was stopped due to the accelerated growth of SCC in this patient. Uneventful excisions of all the SCC lesions were performed and the patient has been regularly followed-up for her GIST and SCC.

Case Report 2. The second case involves a 61-year-old woman, with past medical history remarkable for rheumatoid arthritis, who presented to our institution with a rash $2 \mathrm{~cm}$ from the anal verge. Upon further questioning, the patient reported that she had experienced leakage of a small amount of stool and also passing of a small amount of bright red blood in her stool over the past many months. On physical examination, a palpable mass was present just proximal to the anal verge. Imaging and a rectal EUS with fine-needle aspiration biopsies were obtained and pathology was consistent with rectal GIST.

The patient underwent neoadjuvant treatment with 400 $\mathrm{mg}$ /day imatinib (Gleevec ${ }^{\circledR}$, Novartis), followed by a successful rectal resection of the tumor. After 1 year, the patient underwent a follow-up examination and post-surgical imaging was ordered. This showed possible residual disease. Therefore, it was decided to restart imatinib postoperatively on a dose of $400 \mathrm{mg}$ daily.

On 4 months of imatinib therapy, the patient developed mouth sores, worsening fatigue and appetite, as well as facial swelling, thought to be due to imatinib. The medication was reduced to $200 \mathrm{mg}$ daily due to these side-effects.

On 9 months of imatinib therapy, the patient developed illmarginated, erythematous, rough papule following imatinib on both of her legs (calves) (Figure 2). Skin biopsy of one of the lesions showed aggregates of pleomorphic keratinocytes with nuclear atypia, hyperkeratosis and dyskeratosis in the epidermis. These lesions were consistent with actinic keratosis, which is widely accepted as a precursor to SCC formation.

On 1 year of imatinib treatment, the cutaneous lesion in our patient had progressed to SCC. Imatinib was discontinued immediately and the SCC was managed successfully with surgical resection. However, unfortunately, we were unable to collect the complete data regarding SCC of this patient.

\section{Discussion}

The worldwide incidence and prevalence of GISTs are estimated to be approximately 1 to 1.5 per 100,000 per year and 13 per 100,000, respectively (1). Most (50-80\%) GISTs arise from a mutation in the c-KIT gene, which encodes a receptor for a growth factor termed stem cell factor (CD117). The c-KIT product is expressed on the interstitial cells of Cajal and a large number of other cells (e.g. bone marrow cells, mast cells, melanocytes). Mutations permit c-KIT to function 
A

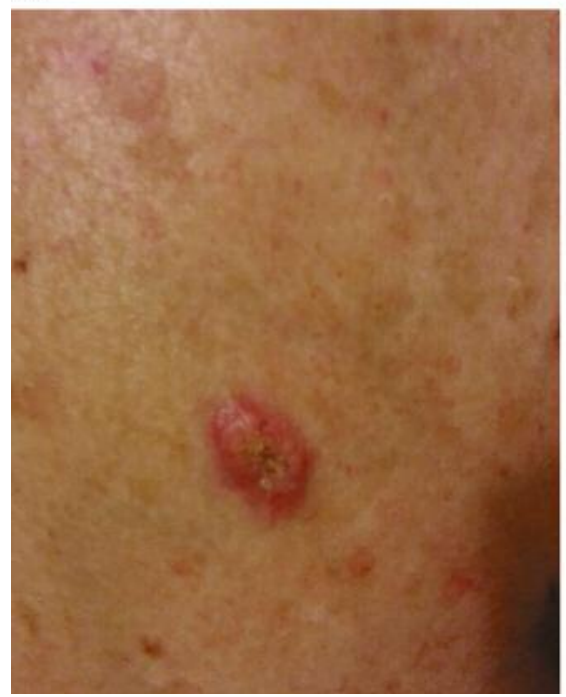

B

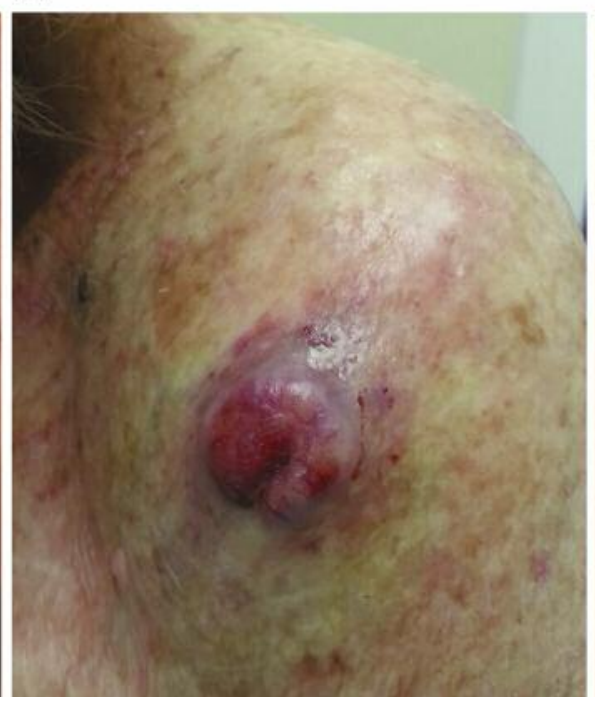

C

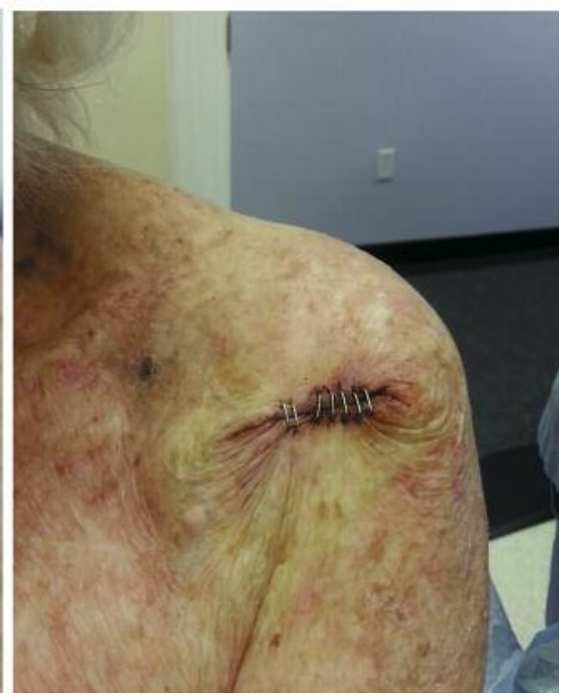

Figure 1. Case 1. A: Initial small superficial mass on left anterior shoulder following imatinib. B: Progression to a 3-cm, ulcerated, reddish nodule with an erythematous halo. C: Excisional biopsy was performed and the specimen was sent for histopathological analysis, which revealed moderately atypical squamous cells with frequent mitoses and small focal areas of keratinization, areas with glandular differentiation and mucin deposition highlighted with Mucicarmine stain.

independent of CD117 activation, which leads to a high rate of cell division and genomic instability. It is likely that more mutations are needed for a cell with a c-KIT mutation to develop into a GIST, but the c-KIT mutation is probably the first step of this process (2). In GISTs, imatinib acts through inhibition of the c-KIT pathway, rather than tyrosine kinase inhibition, as in chronic myeloid leukemia (3-5).

Imatinib typically has mild to moderate adverse events that are usually managed without permanent cessation of the drug in patients with GISTs (6). In literature, the most commonly reported side-effects included edema (74\%), nausea $(52 \%)$, diarrhea (45\%), myalgia (40\%), fatigue (35\%), skin rash (30\%), headache $(30 \%)$, abdominal pain (26\%), and, rarely, serious gastrointestinal bleeding (2). Another study showed that imatinib was well-tolerated over a long duration with no serious adverse effects (7). In one report on the incidence and frequencies of adverse events in adjuvant randomized trials with imatinib, 30\% patients developed serious adverse reactions (8).

Among patients with GISTs who undergo treatment with imatinib, around $30-44 \%$ exhibit cutaneous adverse reactions. These skin lesions usually arise early in the treatment and are mostly dose-dependent $(9,10)$. Erythematous and maculopapular pruritic rash, appearing predominantly on the forearms and trunk are the most frequently reported skin reactions with imatinib. The rash is typically mild, often selflimiting, and managed conservatively, without the need of imatinib discontinuation. However, 2-3\% of the cases may develop serious cutaneous reactions requiring the immediate cessation of imatinib therapy. In such cases, oral glucocorticoid

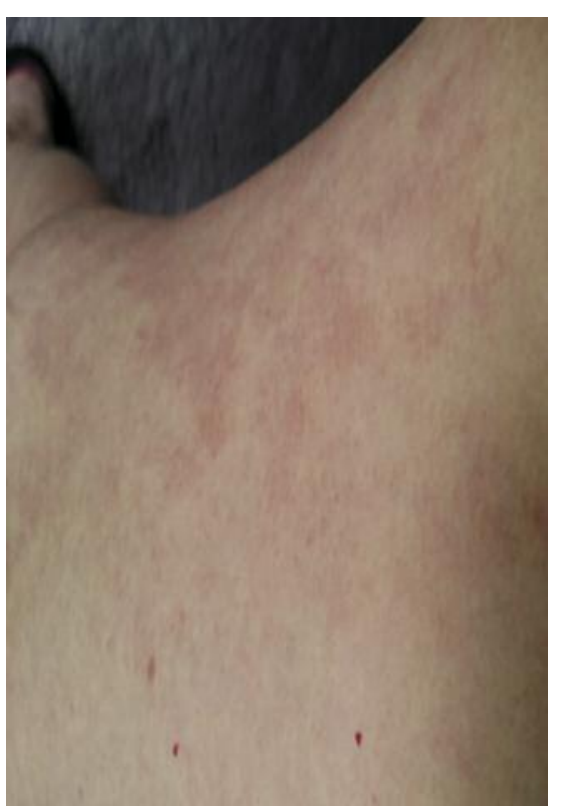

Figure 2. Case 2, multiple ill-marginated, erythematous rough papules following imatinib, on both calves.

may also be administered and tapered off followed by gradual restart of imatinib therapy $(11,12)$. Erythema multiform and Stevens-Johnson syndrome in patients with chronic myeloid leukemia has also been reported, which resolved after imatinib discontinuation and appropriate treatment $(13,14)$. 
Previously, there have been reports of patients with chronic myeloid leukemia who developed SCC due to imatinib therapy $(4,5)$ (Table I). However, SCC in patients with GISTs undergoing treatment with imatinib has never been described in the literature. SCC is the most common type of cutaneous cancer after basal cell carcinoma. It typically appears as a papule or nodule, with varying degrees of hyperkeratosis and ulceration, which arises on sun-exposed skin areas of elderly patients. The incidence of this neoplasm among Caucasians is $100-150$ per 100,000 persons each year, and the age-specific incidence among persons over the age of 75 years is approximately 10 -times that rate (15).

The most common etiological factor behind SCC is ultraviolet radiation. Such radiation frequently produces point mutations in double-stranded DNA, resulting in the formation of thymidine dimers in the p53 tumor-suppressor gene. Failure of repair mechanisms may then lead to tumor formation. Furthermore, SCC has also been associated with immunosuppression, arsenic exposure, radiation, chronic ulceration, and human papillomavirus infection. The specific pathogenesis of cutaneous reactions secondary to imatinib is yet to be determined; however, its high prevalence and dose-dependency suggest that these reactions are possibly mediated by KIT and PDGFRA inhibition in dermal and epidermal cells $(10,11,16)$. Further studies are warranted in this regard.

\section{Conclusion}

While cutaneous SCC usually responds well to surgical intervention, it has the potential to recur locally and even metastasize, leading to significant morbidity and mortality (1719). Therefore, close monitoring of patients with GISTs undergoing therapy with imatinib is of paramount importance in order to diagnose such severe reactions early and institute effective treatment.

\section{Funding and Conflicts of Interest}

The Authors report no biomedical financial interests or potential conflicts of interest in regard to this article.

\section{References}

1 Nishida T, Blay JY, Hirota S, Kitagawa Y and Kang YK: The standard diagnosis, treatment, and follow-up of gastrointestinal stromal tumors based on guidelines. Gastric Cancer 19: 3-14, 2016.

2 Demetri GD, von Mehren M, Blanke CD, Van den Abbeele AD, Eisenberg B, Roberts PJ, Heinrich MC, Tuveson DA, Singer S, Janicek M, Fletcher JA, Silverman SG, Silberman SL, Capdeville R, Kiese B, Peng B, Dimitrijevic S, Druker BJ, Corless C, Fletcher $\mathrm{CD}$ and Joensuu $\mathrm{H}$ : Efficacy and safety of imatinib mesylate in advanced gastrointestinal stromal tumors. N Engl J Med 347: 472480, 2002.

3 Ben Ami E and Demetri GD: A safety evaluation of imatinib mesylate in the treatment of gastrointestinal stromal tumor. Expert Opin Drug Saf 15: 571-578, 2016.
4 Baskaynak G, Kreuzer KA, Schwarz M, Zuber J, Audring H, Riess H, Dörken B and le Coutre P: Squamous cutaneous epithelial cell carcinoma in two CML patients with progressive disease under imatinib treatment. Eur J Haematol 70: 231-234, 2003.

5 Fujii M, Iwasaki T, Takahashi I, Kishiyama K, Honma M, Takahashi H, Ishida-Yamamoto A and Iizuka H: Squamous cell carcinoma in a chronic myelogenous leukemia patient treated with imatinib mesylate. J Dermatol 42: 338-339, 2015.

6 Joensuu H, Trent JC, Reichardt P: Practical management of tyrosine kinase inhibitor-associated side-effects in GIST. Cancer Treat Rev 37: 75-88, 2011.

7 Blanke CD, Demetri GD, von Mehren M, Heinrich MC, Eisenberg B, Fletcher JA, Corless CL, Fletcher CD, Roberts PJ, Heinz D, Wehre E, Nikolova $\mathrm{Z}$ and Joensuu H: Long-term results from a randomized phase II trial of standard- versus higher-dose imatinib mesylate for patients with unresectable or metastatic gastrointestinal stromal tumors expressing KIT. J Clin Oncol 26: 620-625, 2008.

8 Dematteo RP, Ballman KV, Antonescu CR, Maki RG, Pisters PW, Demetri GD, Blackstein ME, Blanke CD, von Mehren M, Brennan MF, Patel S, McCarter MD, Polikoff JA, Tan BR, Owzar K; American College of Surgeons Oncology Group (ACOSOG) Intergroup Adjuvant GIST Study Team: Adjuvant imatinib mesylate after resection of localised, primary gastrointestinal stromal tumour: a randomised, double-blind, placebo-controlled trial. Lancet 373: 1097, 2009.

9 Deininger MW, O'Brien SG, Ford JM, Druker BJ: Practical management of patients with chronic myeloid leukemia receiving imatinib. J Clin Oncol 21: 1637-1647, 2003.

10 Valeyrie L, Bastuji-Garin S, Revuz J, Bachot N, Wechsler J, Berthaud P, Tulliez M and Giraudier S: Adverse cutaneous reactions to imatinib (STI571) in Philadelphia chromosomepositive leukemias: a prospective study of 54 patients. J Am Acad Dermatol 48: 201-206, 2003.

11 Guilhot F: Indications for imatinib mesylate therapy and clinical management. Oncologist 9: 271-281, 2004.

12 Rule SA, O'Brien SG and Crossman LC: Managing cutaneous reactions to imatinib therapy. Blood 100: 3434-3435, 2002.

13 Hsiao LT, Chung HM, Lin JT, Chiou TJ, Liu JH, Fan FS, Wang WS, Yen CC and Chen PM: Stevens-Johnson syndrome after treatment with STI571: a case report. Br J Haematol 117: 620-622, 2002.

14 Vidal D, Puig L, Sureda A and Alomar A: STI571-induced Stevens-Johnson syndrome. Br J Haematol 119: 274-275, 2002.

15 Rinker MH, Fenske NA, Scalf LA and Glass LF: Histologic variants of squamous cell carcinoma of the skin. Cancer Control 8: 354-363, 2001.

16 Lammie A, Drobnjak M, Gerald W, Saad A, Cote R and CordonCardo C: Expression of c-kit and kit ligands proteins in normal human tissues. J Histochem Cytochem 42: 1417-1425, 1994.

17 Alam M and Ratner D: Cutaneous squamous-cell carcinoma. N Engl J Med 344: 975-983, 2001.

18 McMurray HR, Nguyen D, Westbrook TF and McAnce DJ: Biology of human papilloma viruses. Int J Exp Path 82: 15-33, 2001.

19 Harwood CA and Proby CM: Human papillomaviruses and nonmelanoma skin cancer. Curr Opin Infect Dis 15: 101-114, 2002.

Received June 28, 2016

Revised July 18, 2016

Accepted July 21, 2016 